\title{
Impact of Previous Conceptions in Secondary-University Transition: The Case of Conversion of Numerical
}

\section{Sequences}

\author{
Bouchra Litim, Amina Benbachirand Moncef Zaki \\ Interdisciplinary Laboratory of Research in Didactics of Sciences and Technology \\ (ILRDST),Faculty of Sciences.Dhar El Mahraz, Sidi Mohammed Ben Abdellah University, PB: \\ 1796, 30000, Fez, Morocco \\ b.litim@hotmail.com \\ Interdisciplinary Laboratory of Research in Didactics of Sciences and Technology (ILRDST), \\ Faculty of Sciences.Dhar El Mahraz, Sidi Mohammed Ben Abdellah University, PB: 1796, \\ 30000, Fez, Morocco \\ ambenbachir@yahoo.fr \\ Interdisciplinary Laboratory of Research in Didactics of Sciences and Technology (ILRDST), \\ Faculty of Sciences.Dhar El Mahraz, Sidi Mohammed Ben Abdellah University, PB: 1796, \\ 30000, Fez, Morocco \\ zaki.moncef@yahoo.fr \\ In this article, we first present a theoretical study on the status and origin of the conceptions. Then, based on this study, we \\ make a quantitative and, at the same time, a qualitative analysis of the responses of 148 students to a questionnaire on \\ the notion of convergence of numerical sequences. The results of the experiment show that the errors of the students \\ come mostly from previous incorrect conceptions. We think that the traditional teaching method favors the emergence of \\ these conceptions and that the introduction of new teaching methods is needed. Besides the difficulties noted in the \\ resolution of exercises, the composition of answers reveals to us severe language problems related to French \\ expressions, which, in turn, require a reflection on a more adequate content of the teaching of the French language in the
}

\section{ABSTRACT:} first years of university science tracks.

Keywords: Secondary-universityTransition - numerical sequences -obstacles -conception.

Academic: Discipline and sub-disciplines Education, Didactics of Mathematical Sciences

SUBJECT CLASSIFICATION: Innovation in education

\section{Council for Innovative Research}

Peer Review Research Publishing System

Journal: INTERNATIONAL JOURNAL OF RESEARCH IN EDUCATION METHODOLOGY

Vol. 6, No. 3

www.ijrem.com , ijremeditor@gmail.com 


\section{INTRODUCTION}

Several research works were interested in the origins of errors produced by pupils in problem-resolution situationsandin the setting-up of remediation situations (Charnay and Mante, 1992; Astolfi , 1997). The present work also lies within the framework of this issue with first-year students inthe tracks of Mathematical Sciences and Applications(MSA) and Mathematical Sciences andComputing (MSC)at the Faculty of Sciences Dhar El Mahraz in Fes, Morocco.

The exams at the end of the first semester in 2012, led to an acknowledgement of massive failure of these students, particularlyin relation to questions about the treatment of the convergence of numerical sequences. Therefore, we thought of preparing a questionnaire for them in order to identify the origins of their mistakes and difficulties, to uncover the existence of possible regularities in their erroneous answers in order to develop an experimental didactic sequence, based on didactic situations of remediation.

The questionnaire that was developed was designed on the basis on four exercises related to the notion of convergence of numerical sequences. This choice was motivated by various reasons.

First of all, this concept has a fundamental place in the teaching mathematics; it is taught as early as the last year of secondary school and throughout the first two years of University. Moreover, over the past years at various evaluations, we have been able to see that this part of the course of mathematical analysis is the source of many difficulties for students. This finding is confirmed by several studies, In particular those of Aline Robert $(1982,1983)$.

From a didactic point of view, the construction of knowledge occurs primarily through the action and expression of students' representations; but theseconceptions can sometimes turn into obstacles (Asttolfi and Peterfalvi,1993; Astolfi and Develay,1987; Giordan,1996). We, therefore,sought to answer the following question:

What is the impact of students' previous conceptionson the resolution of exercises?

To give an answer to this question, we referred to the theory of situations of Guy Brousseau (1986) to set a theoretical framework for the analysis and interpretations of students' errors.

\section{THEORETICAL FRAMEWORK}

\subsection{Conceptions and Obstacles}

The works of Brousseau show that an error is not only due to ignorance, but also to uncertainty or it is random, as is often presented in empiricist or behaviorist theories of learning, but it is the effect of previous knowledge that has been engaged with some success in a set of actions which proves false or inappropriate in other situations. Such a conception will be difficult to remove, and will hinder any new learning. These resultsshed light on the major importance of previous conceptions in learning new knowledge and on the fact that the analysis of students' conceptions can help us identify obstacles, as rightly pointed outin (AstolfiandPeterfalvi, 1993): "Various representations which relate to seemingly unrelated concepts may appear in the analysis as the emergence points of the same obstacle."

Brousseaudistinguishe three typesof obstacles:

- Ontogenetic-origin obstacles: those that arise out of neurophysiological and other limitations of the subject at a given time of its development.

- Didactic-origin obstacles: they depend on a choice of an educational system.

- Epistemological-origin obstacles: they are found in the history of the concepts themselves

(Brousseau, 1983).

Thus, the analysis of students' conceptions can help us identify the nature of the obstacles; it will help us in this case build later didactic situations aroundnumerical sequences, according to modalities of learning that are going to allow the students to better overcome their difficulties.

\subsection{Obstacles relating to the teaching the convergence of numerical sequences}

\subsubsection{Obstacles of an epistemological order}

Certain notions in mathematics possess formalizing,unifying and generalizing characters at the same time, denoted by the symbol "FUG". These are as follows (Vanderbrouck and al 2008):

- The formalizing character: a new formalism is introduced with the use of mathematical symbols.

- Thegeneralizingcharacter: the new concept is an extension of an old one.

- The unifying character: the new concept replaces several old items.

The notion of convergence of numerical sequences is a perfect example. By its FUG nature, it causes difficulties in teaching and learning among students (Robert,1998). 


\subsubsection{Obstacles associated with didactic transposition: didactic-origin obstacles}

Traditionally, in secondary education, the notion of convergence of numerical sequences is introduced in a formal way, by presenting definitions that involve knowledge of mathematical logic, especially as it relates toquantifiers and logical implications. However, this knowledge is not generally subject to any specific high school instruction (Chelougui ,2004) as is the case in Morocco. Thus, a formal presentation of the concept of convergence of numerical sequences, resulting in a didactic transposition, will certainly become a difficulty that turns into anobstacle for students (see1.2).

\section{TESTING AND EXPERIMENTATION}

The weekly teaching of analysis in the first year of university for the tracksSMA and SMI is made up of two lectures (in an amphitheater) of 2 hours each, for which a handout of lecture notes is available for the students, and three sessions oftutorial classes (TC) $1 \mathrm{~h} 30$ for each. Traditionally, the formal lecture begins one week before the TC.The test was thus proposed that week before the TCon September2013 to 148 students of the SMA and SMI tracks. The test contained four exercises (Cf. Appendix)that were meant to be taken in 1h30. For the design of these exercises, we have taken into account the results of an analysis of 330 papers of theanalysis exam paper of the previous year (February 2012), taking into account the work of Aline Robert (1982, 1983, 1998).

\section{ANALYSIS AND INTERPRETATION OF RESULTS}

We shall limit ourselves to the productions of the students relative to exercises 2 and 3 , which represent rich and exhaustive results.

\subsection{Analysis of results for exercise 2}

Exercise 2 is concerned with the definition of a divergent sequence and the production of two examples of divergent numerical sequences.

A) To the question of the definition of a divergent numerical sequence,the results were as follows: $76.3 \%$ wrong answers, $20.3 \%$ non-response, and only $3.4 \%$ correctresponse (see Fig.1). On all the wrong answers, here's the list of the most common errors:

$$
\forall \varepsilon>0 \exists n_{o}>0 \text { such as : } \forall n<n_{o},\left|U_{n}-l\right|>\varepsilon
$$

- $\left(U_{n}\right)$ divergent then $\left(U_{n}\right)$ is increasing and is not bounded.

- A divergent result is a non-increasing sequence plus or minus non-decreasing.

- $\quad\left(\mathrm{V}_{\mathrm{n}}\right)$ divergent then $\exists \varepsilon>0, \forall \mathrm{n} \in \mathrm{N}_{3}\left|V_{n}-l\right| \geq \varepsilon$.

- $\lim \cup_{\mathrm{n}}=+\infty<=>\exists A>0, \forall n_{o} \in N / n \geq n_{o} U_{n}>A$

- $\lim U_{n}=-\infty<=>\exists A<0, \forall n_{o} \in N / n \geq n_{o} U_{n}<-A$

- $\left(\cup_{n}\right)$ is divergent if it is neither increasing nor decreasing.

First, we notice that the students who produced these responses relied on their memory to reconstruct the definition without success: this simply reflects a loss of sense of this notion among these students.

On the other hand, for some students, "a sequence is divergent if and only if it tends to infinity": this is explained by the effect of type of exercises on divergent sequences treated mostly in high school (few exercises relatingto sequences whose general term has no limitare treated in the final year of high school). Furthermore, we identify the misconception which is that a "sequence is convergent if and only if it is monotonic." This conception is also at the origin of the following false conjecture "a divergentsequences is neither increasing sequence nor decreasing." We believe that this conceptionis partly due to aconfusion between the implication and equivalence, hence a lack of mastery of the fundamental tools of mathematical logic.

Finally, in general, students'incorrect answers reflect a master writing formalism. Previous teaching practices at high school seem not to have respected the conditions favorable to a successful didactic transposition. Difficulties of interpretation of symbolic writing encountered by students were thus transformed into obstacles facing the understanding of the concept of divergentsequences.

B) For the question related to the production of two examples ofdivergent sequences, we obtained $33.8 \%$ of nonresponses (see Fig.1). Otherwise, the majority of correct answers gave examples of sequences which tend to infinity. In addition, $14.9 \%$ of students gave one example, which is often $\left(U_{n}\right)$ such that: $U_{n}=(-1)^{n}$ and this is an example that has already been in class. 
These results simply indicate that students have many difficulties to produce examples. This is not a surprise for us, as students don't master the concept definition of divergent sequences.

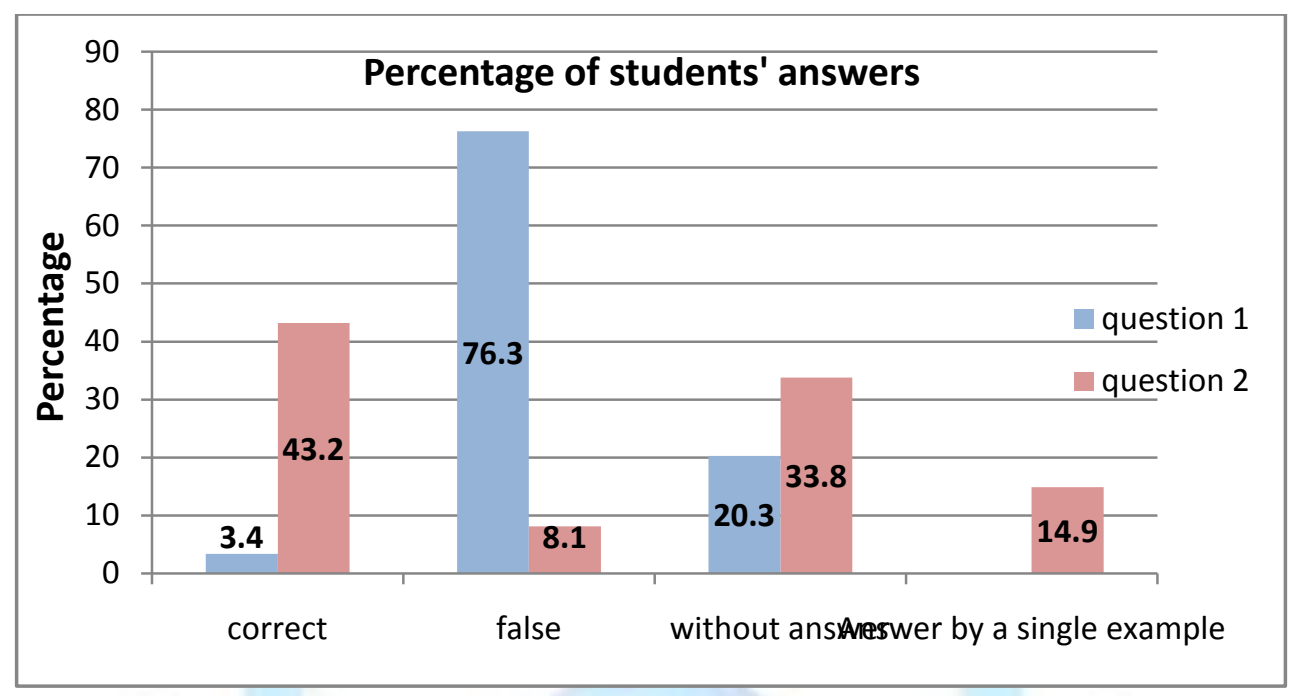

Fig.1

\subsection{Analysis of the results for exercise 3}

The statement of this exercise is the following: Let $\left(U_{n}\right)_{n \geq 1}$ anumerical sequences set

$$
U_{n}=\frac{(-1)^{n}}{n}
$$

Are the following statements true or false? Justify your answers

i) $\left(U_{n}\right)_{n \geq 1}$ is decreasing

ii) $\left(U_{n}\right)_{n \geq 1}$ is increasing

iii) $\left(\cup_{n}\right)_{n \geq 1}$ is bounded

iv) $\left(U_{n}\right)_{n \geq 1}$ is convergent.

The objective of this exercise is to treat an example of a boundedconvergent sequence which is neither increasing nor decreasing.

\subsubsection{Analysis of items i) and ii)}

In the analysis of the answers, we treated questions i) and ii) as a single question (see Fig.2). The most frequent errors we met are the following:

- $n$ pair, then $\left(U_{n}\right)$ is increasing.

- $n$ odd, $\left(U_{n}\right)$ is decreasing.

- $\frac{U_{n+1}}{U_{n}}=\frac{-n}{n+1}<1, \forall n \geq 1(-1)^{n} \geq 1$, therfore $\left(\mathrm{U}_{\mathrm{n}}\right)$ is decreasing.

Out of the 148 students that were questioned, 65 students distinguished the two cases $\mathrm{n}$ pair and $\mathrm{n}$ odd. They deduced that the sequence is increasingif $n$ ispair, and decreasing if $n$ is odd. This large number of students did not taken into account that in the definition of an increasing sequence (respectively decreasing), the inequality $U_{n+1} \geq U_{n}$ (respectively

$\left(U_{n+1} \leq U_{n}\right)$ must be checked for any $n \geq n_{0}$.

In addition, 18 students calculatedthe rapport $U_{n+1} / U_{n}$ to deduce that $\left(U_{n}\right)$ is decreasing. These students remembered the proposition of the course, but did not take into account the adequate conditions of its use (the positivity of $\left(\cup_{n}\right)$ ). We can find an explanationfor these serious procedures in the study of Françoise Boshet (1983). The latter showed that an oral discourse (in the lecture) is structured as a sequence of statements and demonstrations followed by comments at the peri-mathematic level in a quantity that is at least as much important, but in the notes taken by students during the course this peri-mathematical discourse leaves no traces there. She even noticed that students also deleted mathematical information written on the board.

We also noted in the majority of wrong answers the idea that "a sequence is either increasing or well decreasing." Some students even consider a "sequence can be both at the same time." 


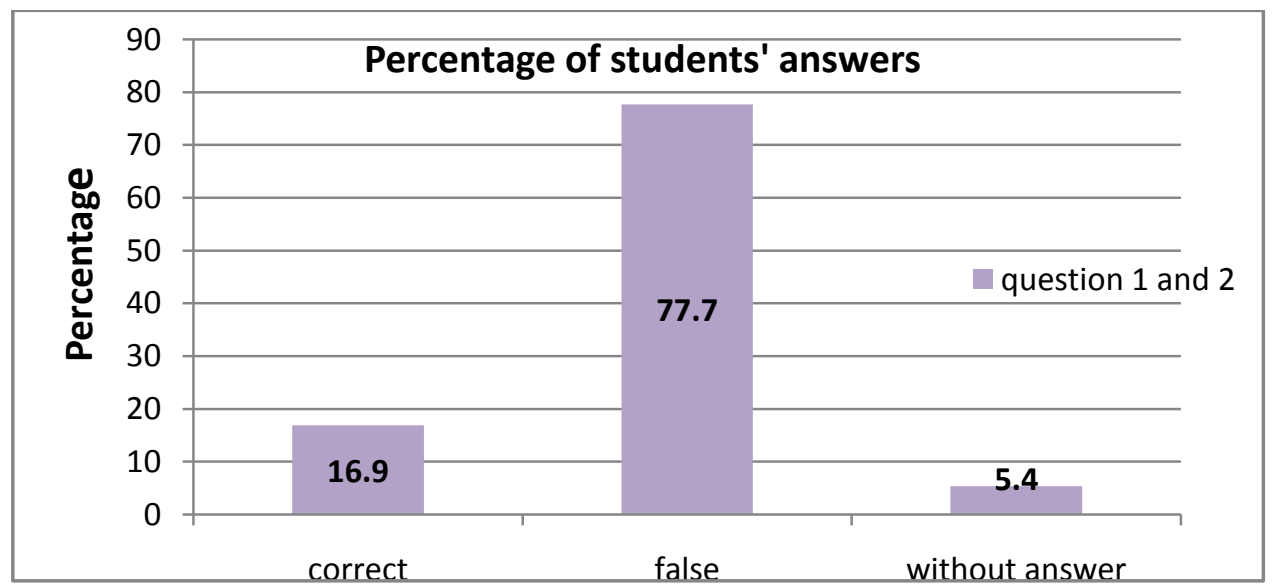

Fig.2

\subsubsection{Analysis of item iii)}

This question gave $77.7 \%$ of non-responses (see Figure 3). In addition, 14 students framed (Un) between two terms which depend on $n$, then they concluded that $\left(U_{n}\right)$ is bounded without taking into account the variable character of $n$, which is a nonsense of the concept enof bounded sequence.

We also noticed coarse procedures in the treatment of inequalities multiplications, such as:

$$
-1 \leq\left(-1^{n}\right) \leq 1 \text { and } 0<\frac{1}{n}<1 \text { whence } 0<(-1)^{n} \cdot \frac{1}{n} \leq 1
$$

The most surprising answer to the question, some students used false conjectures made by themselvessuch as the following:

" $\left(\cup_{n}\right)$ is neither increasing nor decreasing, so it is not convergent."

\subsubsection{Analysis of the item iv)}

For this question, we found $28.4 \%$ of non-responses. Moreover, the rate of false responses amounted to $56.1 \%$ and the most common errors were:

- $\left(U_{n}\right)$ is not increasing or decreasing, so it is not convergent.

- $\left(\mathrm{U}_{\mathrm{n}}\right)$ is increasing, decreasing and bounded, so it converges

In the process of linking the convergence of the sequence to its monotony,we see here "a kind of equivalence relation" obtained by truncating theorems. This shows that these misconceptions are very tough and are going to require major didactic efforts to be eliminated.

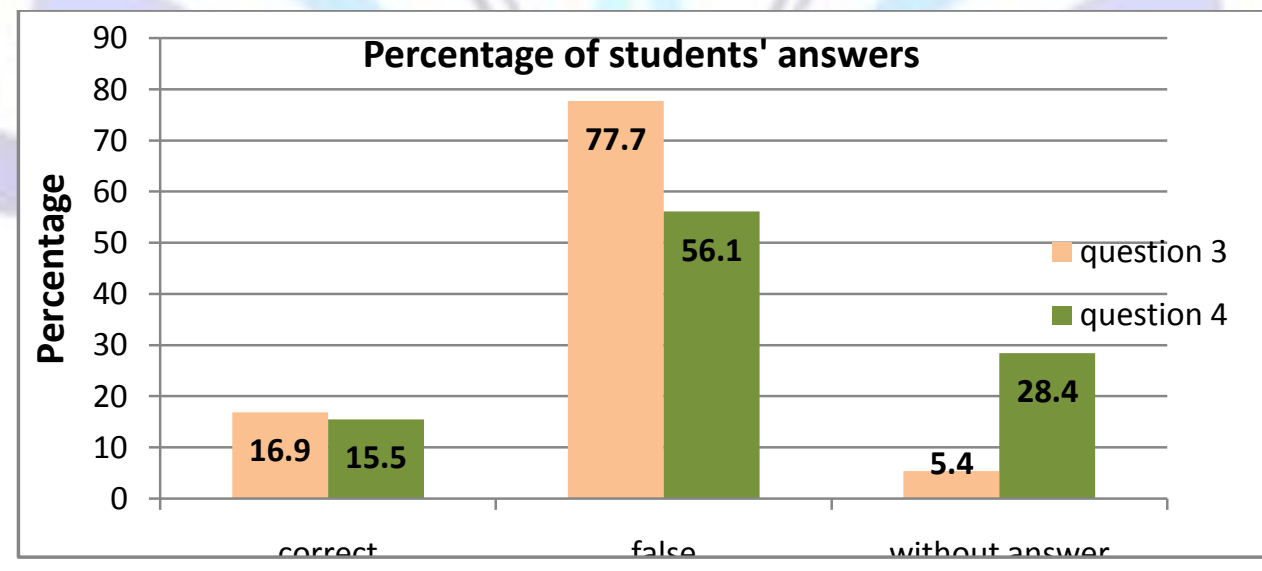

Fig.3 
Some remarks on students' writing:

Many students wrote answers with total incoherence, from a textual rather than a mathematical point of viewtheir formulations testified sometimes of a very high no mathematical sense. Here are some very striking examples:

On... dit ....que......urse.... Suite ....est.... divergente

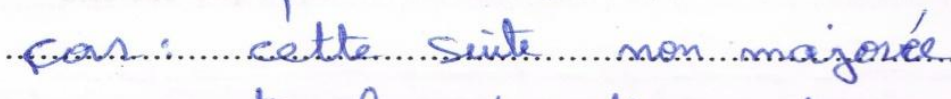

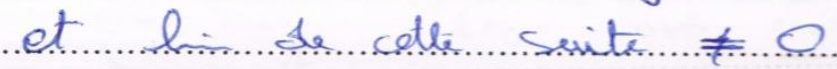

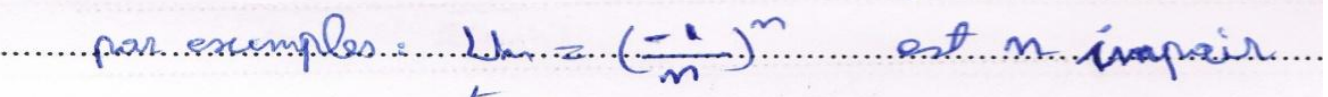

et.............

L),$\ldots=(-\ldots .1)^{m}$

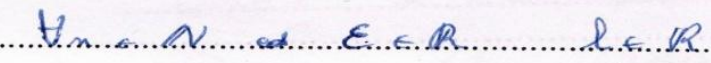

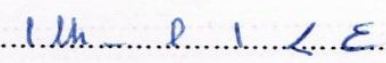

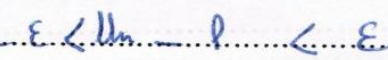

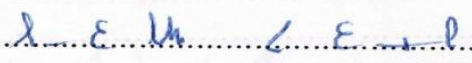

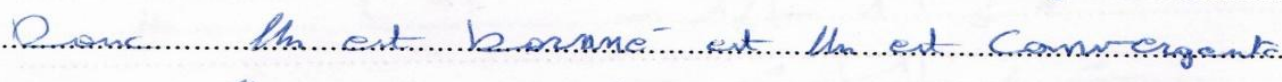

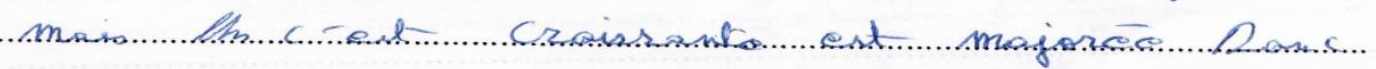

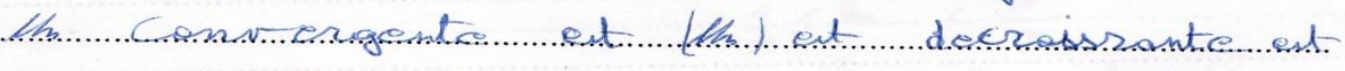

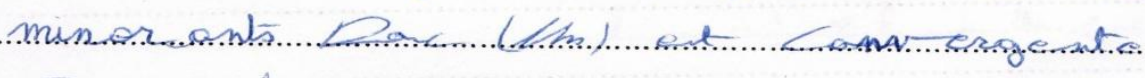

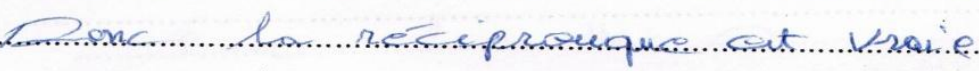

En Greneral tonte orite nonotone Comulna Mna que chre grite decorishante nienorée converge ent

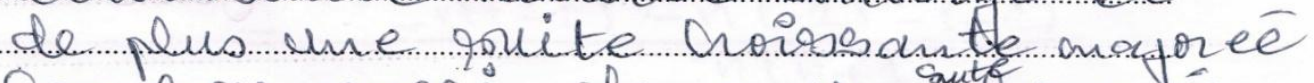

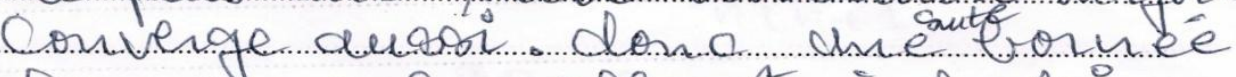
cona vage da elle eft à la foin. maforếent minor ếe

Pax Contre la reciproque est fousse

Car une quite pert tôtre borulée

e t ne pow ôtre croiosolute on

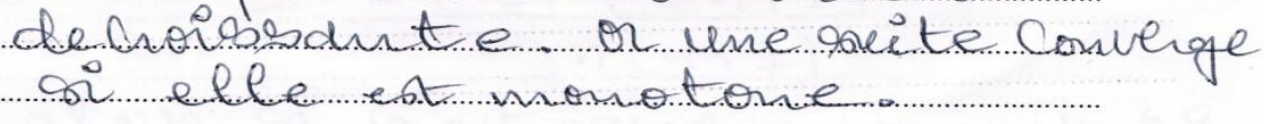

We attribute many of these difficulties to the Arabization of science subjects in secondary education, knowing thatat university level,French remains the language of instruction of these subjects.Conceptual difficulties that we have identified, added to a lack of mastery of the language of expression, make didactic work on the mathematical contents alone not sufficient. It should also work on improving the linguistic level of students. Moreover, the linguistic difficulties of the students must certainly constitute an important obstacle in their mathematical apprehensions. 


\section{CONCLUSION}

The analysis of the students' answers to the test revealed that their errors are not due to mere forgetfulness, but rather to previous misconceptions developed during secondary education. Furthermore, these conceptual difficulties are mainly due to educational obstaclesrelated to didactic transposition that does not take into account the nature of the FUG notion of convergence of numerical sequences. Thus, in general, we put into question traditional teaching practiceswhich , it seems to us, are at the origin of these obstacles. In addition, given the textual inconsistencies in the students' writing, it appearsto be necessary to rethink the content of the course of Expression and Communication Techniques taught during the first two years in Moroccan universities.

The results of this pre-test led us to develop a teaching experiment with these students, in the form of a didactic engineering based on "scientific debate" (Legrand, 1993), developed by the latter from the theory of situations of Guy Brousseau (1986) and the anthropological theory of Chevallard Yves (1991). In fact, we start from the strong hypothesis that scientific debate will enable the student to get involved in the construction of their knowledge and promote the development of cognitive conflict necessary for a deeper understanding. The choice of scientific debate among students was guided by previous research conducted at the laboratory LIRDIST (Benbachir and Zaki, 2001), which showed that the confrontation of arguments of students in problem solving allowed to clearly identify the main difficulties related to the control of the analysis of functions in the first year of university.

Finally, due to reasoning and logical processingerrors identified in the students' responses to thetest, we will therefore pay particular attention to modes of mathematical reasoning as well as formalism and symbolicwriting,which will be used by the students during the sessions of scientific debate. This is in the hope of bringing improvement and more competence in the reasoning and mathematical formulations of the students.

\section{REFERENCES}

[1] Astolfi, J.P.,and Devalay, M.1989. La didactique des sciences.Paris, P.U.F.,1989.

[2]Astolfi, J.P.,and Peterfalvi ,B.1993. Obstacles et construction de situations didactiques en sciences expérimentales. Aster, 16 : Modèles pédagogiques 1. pp.103-141.

[3] Astolfi, J.P. 1997. L'erreur, un outil pour enseigner, Paris. ESF, collection Pratiques \&enjeux pédagogiques.

[4] Benbachir, A., andZaki, M. 2001. Production d'exemples et de contre-exemples en analyse : étude de cas en première année d'université. Educational Studies in Mathematics, vol. 47, 273-295.

[5] Boshet, F. 1983.Les suites numériques comme objet d'enseignement. Recherche en didactique des mathématiques, vol $4, \mathrm{n}^{\circ} 2,141-163$.

[6] Brousseau, G. 1982.Ingénierie didactique, Actes de la seconde école d'été de didactique des mathématiques, IREM d'Orléans.

[7] Brousseau, G. 1983. Les obstacles épistémologiques et les problèmes en mathématiques. Recherche en didactique des mathématiques, vol. 4.2,167-189.

[8] Brousseau, G. 1986. La théorie des situations, RDM, vol.7.2, éd la pensée sauvage, Grenoble.

[9] Charnay, R., and Mante, M .1992.De l'analyse d'erreurs en mathématiques aux dispositifs de remédiation, quelques pistes. Repères-IREM, $\mathrm{n}^{\circ} 7,1992$.

[10] Chellougui, F. 2003. Approche didactique de la quantification dans la classe de mathématiques dans l'enseignement tunisien.Petit, $x, n^{\circ} 61,11-34$.

[11] Chevalard, Y. 1991. Concepts fondamentaux de la didactique : perspectives apportées par une approche anthropologique.Recherches en didactique des mathématiques, vol.12/1, 73-112, éd la pensée sauvage, Grenoble.

[12] Develay, M. 1992. De l'apprentissage à l'enseignementPour une épistémologie scolaire,Paris. ESF.

[13] Doise, W., andMugny, G. 1997.Psychologie sociale et développement cognitif, Ed Armand colin, Paris.

[14] Giordan, A.1996. Les conceptions de l'apprenant : Un tremplin pour l'apprentissage. Sciences humaines, hors- série, $\mathrm{n}^{\circ} 12,48-50$.

[15] Joshua, S.,and Duppin, J.J. 1993. Introduction à la didactique des sciences et des mathématiques. Paris : Presse universitaire de France, 336.

[16] Legrand, M. 1993. Le débat scientifique en cours de mathématiques. Repères IREM, $n^{\circ} 10$.

[17] Robert, A. 1982. Acquisition de la notion de convergence des suites numériques dans l'enseignement supérieur. Thèse de doctorat d'état. Université de Paris VII.

[18] Robert, A. 1983. Acquisition de la notion de convergence des suites numériques dans l'enseignement supérieur. Recherches en didactique des mathématiques,vol.3, $n^{\circ} 3,305-341$.

[19] Robert, A. 1998. Outils d'analyse des contenus mathématiques à enseigner au lycée et à l'université. Recherche en Didactique des mathématiques, 18/2, 138-190. 
[20] Vandebrouck, F. Students' activities and Teachers' practices. MathematicsClassrooms,264 pages, Rotterdam: Sense Publishers.

\section{APPENDIX}

$\underline{\text { Test }}$

\section{Exercice.1:}

Show that if $\left(U_{n}\right)$ is convergent then it is bounded. The converse is true?

\section{Exercice.2:}

Define a divergentsequence, give two examples.

\section{Exercice.3:}

Let $\left(U_{n}\right)$ be the sequence given by: $U_{n}=\frac{(-1)^{n}}{n}$

The following statements are - true or false? Justify your answers
i) $\left(U_{n}\right)$ isdecreasing
ii) $\left(U_{n}\right)$ is increasing
iii) $\left(U_{n}\right)$ is bounded
iv) $\left(U_{n}\right)$ isconvergent.

\section{Exercice.4}

Let $\left(U_{n}\right)$ be the sequence given by: $U_{n}=\frac{1}{n+1}+\frac{1}{n+2}+\cdots+\frac{1}{2 n}$

The following statements are true or false? Justify your answers: i) $\left(U_{n}\right)$ is bounded above

ii) $\left(U_{n}\right)$ is increasing

iii) $\left(\cup_{n}\right)$ is convergent. 